\title{
PENDIDIKAN KARAKTER PADA ANAK PERSPEKTIF WASHOYA AL ABAA' LIL ABNAA' KARYA SYAIKH MUHAMMAD SYAKIR
}

\author{
Nor Mubin \\ Sekolah Tinggi Agama Islam Daruttaqwa Gresik, Indonesia \\ Email: normubin@staidagresik.ac.id
}

\begin{abstract}
Abstact: The position of character in Islamic education is seen as very important, because character is the practice of knowledge, character is also seen as an effective medium for receiving divine nurses and a means of seeking useful knowledge. Based on these problems, this research emerged. This research is based on library research, with descriptive analysis method. The concept of character education in children globally and the concept of character education in children in the perspective of Washoya Al Abaa 'Lil Abnaa'. Starting from the findings of this study, there are few suggestions that the education process is built on the basis of character and character education. kindness from a student and sincere love from an educator. The educational process can be conveyed in a good manner. There are 18 values of character education that come from religion, Pancasila, culture, and the goals of national education, namely: Religious, honest, tolerance, discipline, hard work, creative, independent, curiosity, national spirit, love for the country, respect for achievement, friendly or communicative, love peace, love to read, care about the environment, care about social, responsibility. In general, there are five character education methods that teach conceptual understanding, modeling, determining priorities, priority practice, reflection. While the character education method in the Washoya Al-Abaa book 'Lil Abnaa' can be concluded as a discussion method, memorization method, advice method (mau'izhah), habituation method, story method, exemplary method, dialogue method, targhib wa tahdib method, targhib method. wa tahdib.
\end{abstract}

Keywords: Character and Child Education

\begin{abstract}
Abstak: Kedudukan karakter dalam pendidikan islam dipandang sangat penting, karena karakter merupakan pengamalan dari ilmu, karakter juga dipandang sebagai media efektif penerimaan nur Ilahi dan sarana mencari ilmu yang manfaat. Berdasarkan persoalan tersebut, penelitian ini muncul. Penelitian ini berbasis library research, dengan metode analisis deskriptif. Konsep pendidikan karakter pada anak secara global dan konsep pendidikan karakter pada anak perspektif Washoya Al Abaa' Lil Abnaa'. Bertitik tolak dari temuan kajian ini, sedikit saran agar proses pendidikan dibangun atas dasar pendidikan karakter dan budi pekerti. yang baik dari seorang murid dan cinta kasih yang tulus dari seorang pendidik. Proses pendidikan tersebut dapat disampaikan secara berbudi pekerti yang baik. Ada 18 nilai pendidikan karakter yang bersumber dari agama, pancasila, budaya, dan tujuan pendidikan nasional, yaitu: Religius, jujur, toleransi, disiplin, kerja keras, kreatif, mandiri, rasa ingin tahu, semangat kebangsaan, cinta tanah air, menghargai prestasi, bersahabat atau komunikatif, cinta damai, gemar membaca, peduli ligkungan, peduli social, tanggung jaw ab. Metode pendidikan karakter secara umum ada lima mengajarkan pemahaman konseptual, keteladanan, menentukan prioritas, raktis prioritas, Refleksi. Sedangkan metode pendidikan karakter dalam kitab Washoya Al-Abaa' Lil Abnaa' dapat disimpulkan menjadi metode diskusi, metode menghafal, metode nasehat (mau'izhah), metode pembiasaan, metode kisah, metode keteladanan, metode dialog, metode targhib wa tahdib, metode targhib wa tahdib.
\end{abstract}

Kata kunci: Pendidikan Karakter dan Anak 


\section{Pendahuluan}

Manusia dilahirkan kedunia ini tanpa pengetahuan apapun, tetapi dalam kelahirannya manusia telah dilengkapi dengan fitrah yang memungkinkannya untuk menguasahi berbagai pengetahuan. Dengan menfungsikan fitrah itu maka diharapkan manusia dapat belajar dari lingkungan dan masyarakatnya. Diantara tanda dari fitrah itu adalah Allah telah menciptakan manusia sebagai makhluk yang paling sempurna dengan menganugrahkan potensi, baik potensi jasmani (fisik), potensi spirirtual (qolbu), maupun potensi akal fikiran. Maka dari potensi yang dimiliki itu manusia diposisikan sebagi makhluk yang paling istimewa dibandingkan dengan makhluk lain. Allah SWT berfirman dalam Al-Qur'an surat At-Tin ayat 4 yang Artinya;

"Sesungguhnya Kami telah menciptakan manusia dalam bentuk yang sebaik-baiknya"."

Berbicara tentang pendidikan sesungguhnya tidak dapat dilepaskan dari sosok keberadaan guru atau pendidik, karena memiliki arti orang yang mempunyai tugas mendidik. Jadi guru bisa juga disebut pendidik, guru atau pendidik merupakan unsur manusiawi yang menempati posisi yang memegang peranan penting dalam pendidikan. Begitu pula proses pendidikan yang baik baru akan terjadi manakala ada interaksi antara pendidik (guru) dengan anak didik (murid).

Guru dan anak didik adalah dua sosok manusia yang tidak dapat dipisahkan dari dunia pendidikan, boleh jadi dimana ada guru disitu ada anak didik yang ingin belajar dari guru. Sebaliknya, dimana ada anak didik, disana ada guru yang ingin memberikan binaan dan bimbingan kepada anak didik. Tidak sedikit pun dalam benak guru terlintas pikiran negatif untuk tidak mendidik anak didiknya meskipun barangkali sejuta permasalahan sedang merongrong kehidupan seorang guru. ${ }^{2}$

Guru tidak hanya bertugas sebagai pengajar, tetapi juga berperan dalam usaha pembentukan watak, karakter, tabiat, maupun pengembangan sumber daya yang dimiliki oleh anak didik. Prajudi Atmosudirdjo (1982:60) menyebutkan bahwa guru memiliki peran yang sangat besar dalam pendidikan, di pundaknya dibebani suatu tanggung jawab atas mutu pendidikan. ${ }^{3}$ Untuk itu peran guru tidak hanya terbatas pada peran sebagai pengajar, tetapi peran keaktifanya diharapkan mampu mengarahkan, membentuk dan membina sikap mental anak didik atau murid kearah yang lebih baik. Baik peran itu terjadi dalam proses pendidikan secara langsung (di madrasah) maupun tidak langsung (di lingkungan masyarakat). Jenis metode kajian ini menggunakan Metode library research atau studi pustaka yakni serangkaian kegiatan atau kajian yang berkenaan dengan pengumpulan data pustaka ${ }^{4}$. Data pustaka tersebut terbagi menjadi dua yakni data pustaka primer adalah kitab Washoya Al Abaa' Lil Abnaa' Karya Syaikh Muhammad Syakir, dan data skundernya adalah buku-buku atau kitab-kitab yang mendukung penulis untuk melengkapi isi serta interpretasi dari kitab maupun buku dari sumber data primer.

\section{Pendidikan Karakter pada Anak}

Pendidikan merupakan usaha yang dilakukan secara sadar dan jelas memiliki tujuan. Sehingga diharapkan dalam penerapannya ia tidak kehilangan arah dan pijakan. Pendidikan merupakan suatu bimbingan secara sadar oleh pendidikan terhadap perkembangan jasmani dan rohani anak didik menuju terciptanya kepribadian yang utama. ${ }^{5}$ Pendidikan juga merupakan suatu proses yang berkesinambungan yang bertujuan untuk membentuk kedewasaan pada diri anak.

\footnotetext{
${ }^{1}$ Departemen Agama RI, AlQur'an dan Terjemahannya (Jakarta. Dept. Agama RI. 1999) h. 1076.

${ }^{2}$ Hasan Basri, Filsafat pendidikan islam, (Bandung: Pustaka Setia, 2009), h. 58

${ }^{3}$ Martinis Yamin dan Maisah, Standarisasi kinerja guru, (Jakarta: Gaung Persada, 2010), h. 26

4 S. Margono, Metode Penelitian Pendidikan, (Jakarta: Rineka Cipta, 2007), h. 181

${ }^{5}$ Armai Arief, Pengantar Ilmu dan Metodologi Pendidikan Islam, (Jakarta : Ciputat Pers, 2002 ) h. 15
} 
Dari beberapa definisi yang dikemukakan oleh tokoh pendidikan di atas, maka pendidikan adalah proses (usaha) bimbingan secara sistematis dibawah seorang pendidik menuju kearah pembentukan kepribadian yang mulia, yaitu terbentuknya manusia beriman dan bertaqwa serta memiliki kemampuan yang teraktualisasikan dalam hubungannya dengan Tuhan, sesama manusia dan alam sekitarnya secara positif dan dinamis.

Menurut Kamus Umum Bahasa Indonesia karakter adalah tabiat, watak, sifat-sifat kejiwaan, akhlak atau budi pekerti yang membedakan seseorang dengan yang lain. Maknanya dari pengertian pendidikan karakter yaitu merupakan berbagai usaha yang dilakukan oleh para personil sekolah, bahkan yang dilakukan bersama-sama dengan orang tua dan anggota masyarakat, untuk membantu anak-anak dan remaja agar menjadi atau memiliki sifat peduli, berpendirian, dan bertanggung jawab. ${ }^{6}$

\section{Jenis Pendidikan Karakter}

Ada empat jenis karakter yang selama ini dikenal dan dilaksanakan dalam proses pendidikan, yaitu sebagai berikut;

1.1. Pendidikan karakter berbasis nilai religius (konservasi moral), Jenis pendidikan karakter yang menekankan akan pentingnya rasa keimanan, ketakwaan kepada Tuhan dan seluruh ciptaanNya. Tujuan ini hanya dapat direalisasi dengan pendekatan diri kepada Allah SWT hubungan terus menerus antara individu dan pencipta-Nya.

1.2. Pendidikan karakter bernilai budaya (konservasilingkungan), Jenis pendidikan karakter yang menekankan akan pentingnya aspek- aspek budaya, keteladanan tokoh-tokoh, para pemimpin bangsa, apresiasi sastra, pancasila dan budi pekerti. Adapun karakter peduli lingkungan bisa ditunjukan dengan sikap dan tindakan yang selalu berupaya untuk mencegah kerusakan pada lingkungan alam yang terjadi di sekitar kita, termasuk bagian dari lingkungan adalah keberadaan bangsa dan Negara. ${ }^{8}$

1.3. Pendidikan karakter berbasis lingkungan, Lingkungan atau sosial masyarakat, sebagaimana diungkapkan John Dewey, merupakan satu kata yang mengandung banyak arti. Masyarakat ada dari proses berhimpun, saling mengasihi, serta kebersamaan dalam tujuan, kemaslahatan, dan keihlasan untuk mencapai tujuan umum. Karakter ini perlu dikembangkan oleh lembaga pendidikan agar anak didik mengetahui dan mengerti serta melaksanakan apa yang menjadi kewajiban diri sendiri dan orang lain serta tugas atau kewajiban diri sendiri atau orang lain

1.4. Pendidikan karakter berbasis potensi diri (konservasi humanis), Jenis pendidikan karakter yang menekankan akan pentingnya rasa kemandirian dan tanggung jawab, kujujuran atau amanah, dermawan, suka menolong, pekerja keras, percaya diri, baik, dan rendah hati, untuk membangun sebuah pribadi yang kuat.

\section{Tujuan Pendidikan Karakter.}

Tujuan pendidikan karakter adalah terbentuknya manusia yang berakhlak mulia hal ini senada dengan tujuan dari pendidikan Islam sebagaimana pendapat dari Muhammad Athiyah Al-Abrasyi yang dikutip oleh Omar Muhammad Al- Toumy Al-Syaibani telah merumuskan tujuan pendidikan Islam secara umum ke dalam empat tujuan, sebagai berikut; a) Untuk membentuk akhlak mulia,

\footnotetext{
${ }^{6}$ Daryanto dan Suryatri Darmmiatun, Implementasi Pendidikan Karakter di Sekolah, (Malang: Penerbit Gava Media, 2013), h. 63-64.

${ }^{7}$ Hery Noer Aly. dan Munzier S., Watak Pendidikan Islam, (Jakarta: Friska Agung Insani, 2003), h. 151.

8 Akhmad Muhaimin Azzet, Urgensi Pendidikan Karakter di Indonesia” Revitalisasi Pendidikan Karakter Terhadap Keberhasilan Belajar dan kemajuan Bangsa”, (Jogjakarta: Ar-Ruz Media, 2011), h. 88
} 
b) Persiapan untuk kehidupan dunia dan akhirat, c) Persiapan untuk mencari rizki dan pemeliharaan segi kemanfaatannya, d) Menyiapkan pelajar dari segi profesi, teknik dan perusahaan supaya dapat menguasai profesi tertentu dan ketrampilan tertentu agar dapat mencari rizki dalam hidup, disamping memelihara segi kerohanian dan keagamaan. ${ }^{9}$

\section{Nilai Pendidikan Karakter}

Secara umum nilai-nilai karakter atau budi pekerti ini menggambarkan sikap dan perilaku dalam hubungan dengan tuhan, diri sendiri, masyarakat dan alam sekitar, mengutip pendapat Lickona pendidikan karakter secara psikologis harus mencakup dimensi penalaran berlandasan moral (moral reasoning), perasaan berlandasan moral (moral feeling), dan perilaku berasaskan moral (moral behavior).

Dalam rangka lebih memperkuat pelaksanaan pendidikan karakter pada satuan pendidikan telah teridentifikasi 18 nilai yang bersumber dari agama, pancasila, budaya, dan tujuan pendidikan nasional, yaitu: (1) religius, (2) jujur, (3) toleransi, (4) disiplin, (5) kerja keras, (6) kreatif, (7) mandiri, (9) rasa ingin tahu, (10) semangat kebangsaan, (11) cinta tanah air, (12) menghargai prestasi, (13) bersahabat atau komunikatif, (14) cinta damai, (15) gemar membaca, (16) peduli ligkungan, (17) peduli social, (18) tanggung jawab. ${ }^{10}$

Secara psikologis, karakter individu dimaknai sebagai hasil keterpaduan empat bagian yaitu oleh hati, olah pikir, olah raga dan olah rasa dan karsa. olah hati berkenaan dengan perasaan, sikap dan keyakinan atau keimanan. Olah pikir berkenaan dengan proses nalar guna mencari dan menggunakan pengetahuan secara kritis, kreatif, dan inovatif. Olah raga berkenaan dengan proses persepsi, kesiapan, peniruan, manipulasi dan penciptaan aktifitas baru disertai sportivitas. Olah rasa dan karsa berkenaan dengan kemauan, motivasi dan kreativitas yang tercermin dalam kepedulian, citra dan penciptaan kebaruan.

\section{Metode Pendidikan Karakter.}

Doni A. Kusuma mengajukan 5 (lima) metode pendidikan karakter (dalam penerapan di lembaga sekolah) yaitu; 1) Mengajarkan sebagai bekal konsep-konsep nilai, 2) Keteladanan. manusia lebih banyak belajar dari apa yang mereka lihat, 3) Menentukan prioritas, 4) Praktis prioritas dan 5) Refleksi pada kedalam diri, ${ }^{11}$

\section{Faktor-faktor yang Mempengaruhi dalam Pendidikan Karakter Anak}

Karakter berkembang dan mengalami perubahan-perubahan, tetapi di dalam perkembangan itu terbentuk pola-pola yang tetap dan khas sehingga merupakan ciri-ciri yang unik pada setiap individu. Faktor-faktor yang mempengaruhi perubahan watak itu dibagi sebagai berikut;

a. Faktor Sosial, artinya masyarakat atau manusia lain di sekitar individu yang mempengaruhi individu yang bersangkutan. Termasuk ke dalam faktor sosial ini juga tradisi-tradisi, adat istiadat, peraturan- peraturan, bahasa dan sebagainya yang berlaku dalam masyarakat itu sendiri.

\footnotetext{
9 Omar Muhammad Al-Toumy Al-Syaibani, Falsafah Pendidikan Islam, Terj.Langgulung (Jakarta: Bulan Bintang, 1979), h. 436

${ }_{10}$ Pusat Kurikulum, Pengembangan dan Pendidikan Budaya dan Karakter Bangsa: Pedoman Sekolah, 2009, h. 9-10.

11 Doni Koesoema A., Pendidikan Karakter "Strategi Mendidik, Anak di Zaman Global", h. 212-217.
} 
b. Faktor Kebudayaan, aspek kebudayaan yang sangat mempengaruhi pembentukan karakter antara lain dalam setiap kebudayaan terdapat nilai-nilai hidup yang dijunjung tinggi oleh manusia yang hidup dalam kebudayaan dan nilai nilai hidup yang berlaku di masyarakat.

c. Adat dan Tradisi, Adat dan tradisi yang berlaku di suatu daerah di samping menentukan nilainilai yang harus ditaati oleh anggota-anggotanya juga menentukan cara-cara bertindak dan bertingkah laku manusianya

d. Bahasa, merupakan alat komunikasi antara individu yang sangat penting, maka jelas bagaimana sikap dan cara-cara kita bertindak dan bereaksi terhadap orang lain. ${ }^{12}$

\section{Kitab Washoya Al Abaa' Lil Abnaa'karya Syaikh Muhammad Syakir \\ Biografi Syaikh Muhammad Syakir}

Beliau adalah seorang tokoh pembaharu di Universitas Al-Azhar, danjuga sebagai penulis yang produktif yang dikenal sebagai keluarga Abi 'Ulayya' dan keluarga yang dermawan yang telah dikenal sebagai keluarga yang paling mulia dan paling dermawan di kota Jurja. Beliau lahir di Jurja pada pertengahan Syawal tahun 1282 H. Ayahnya bernama Ahmad bin Abdul Qadir bin Abdul Warits. ${ }^{13}$

Beliau menghafal Al-Qur'an dan belajar dasar-dasar studi Islam di Jurja. Kemudian beliau bepergian untuk menuntut ilmu di Universitas Al-Azhar. Pada saat belajar di sana beliau belajar dengan guru-guru besar pada masa itu. Pada tahun $1307 \mathrm{H}$ beliau dipercayai untuk memberikan fatwa dan menduduki jabatan sebagai ketua mahkamah mudiniyah Al-Qulyubiyyah, dan tinggal di sana selama tujuh tahun sampai beliau dipilih menjadi Qadhi (hakim) untuk negeri Sudan pada tahun $1317 \mathrm{H}^{14}$

Pada tahun $1322 \mathrm{H}$, beliau ditunjuk sebagai guru bagi para ulama-ulama Iskandariyyah sampai membuahkan hasil dan memunculkan bagi kaum muslimin, orang-orang yang menunjukkan umat supaya dapat mengembalikan kejayaan Islam di seantero dunia. Selain itu, beliau juga sebagai wakil para guru Al-Azhar, sampai beliau menebarkan benih-benih yang baik ketika itu, beliau menggunakan kesempatan dengan mendirikan Jam'iyyah Tasyni'iyyah pada tahun 1913 H. Kemudian beliau berusaha untuk menjadi anggota organisasi tersebut sebagai pilihannya dari sisi pemerintah Mesir.

Beliau rahimahullah wafat tahun $1358 \mathrm{H}$ yang bertepatan pada $1939 \mathrm{M}$ semoga Allah Ta'ala merahmati beliau dengan rahmat yang luas dan semoga juga terlimpah bagi anak beliau yaitu Al'Allamah Syaikh Ahmad Muhammad Syakir Abil Asybal seorang Muhaddits besar yang wafat pada tahun 1958 M. beliau telah menulis suatu risalah tentang perjalanan hidup ayahnya yang diberi nama "Muhammad Syakir" seorang tokoh dan para tokoh zaman.

\section{Karya-karya Syaikh Muhammad Syakir}

Syaikh Muhammad Syakir telah banyak memberikan kontribusi yang besar bagi dunia Islam. Beliau telah memberikan Ta'lid dan Tahqiq (komentar serta pembahasan yang teliti) kepada banyak karya ulama, diantaranya. ${ }^{15}$

- Tahqiq terhadap Al-Hikam karya Ibnu Hazm

\footnotetext{
${ }^{12}$ Ngalim Purwanto, Imu Pendidikan Teoritis dan Praktis, (Bandung: PT. Remaja Rosdakarya, 2007). h. 158-165

13 Taufik Abdulah, Ensiklopedi Tematis Dunia Islam, Akar dan Awal, (Jakarta: PT. Ikhtiar Baru Van Hoeve, 2002), h.172

${ }^{14}$ Zainuddin, Ahli Hadist, :http://www.ahlulhadis.wordpress.com (diakses pada 25 Maret 2020)

15 Taufik Abdulah, Ensiklopedi Tematis Dunia Islam, Akar dan Awal, (Jakarta: PT. Ikhtiar Baru Van Hoeve, 2002), h.173.
} 
- Tahqiq terhadap Alfiyatul Hadits karya As-Suyuthi

- Takhrij terhadap Tafsir At-Thabrani

- Tahqiq terhadap kitab Al-Kharaj karya Yahya bin Adam

- Ta’lid dan Tahqiq terhadap Al-Muhalla karya Ibnu Hazm

- Tahqiq Syarh Aqidah Thahawiyah

- Syarh Musnad Imam Ahmad (belum selesai sampai beliau wafat)

- Syarh Sunah At-Tirmidzi (belum selesai sampai beliau wafat)

- Umdatut Tafsir Ringkas Tafsir Ibnu Katsir (belum selesai sampai beliau wafat).

\section{Gambaran Kitab Washoya Al Abaa' Lil Abnaa'}

Kitab ini dikarang oleh Syaikh Muhammad Syakir pada bulan Dzul Qo'dah tahun $1326 \mathrm{H}$ atau 1907 M. kitab ini sangat familiar dalam kurikulum pendidikan non formal seperti madrasah diniyah dan pesantren. ${ }^{16}$ Kitab tersebut berisi wasiat tentang moral yang diberikan oleh guru kepada muridnya dalam mengungkapkan nasihat- nasihatnya tentang moral Syaikh Muhammad Syakir menempatkan dirinya sebagai guru yang sedang menasehati muridnya. Dimana relasi guru dan murid diumpamakan sebagaimana orang tua dan anak kandung. Bisa diumpamakan demikian karena orang tua kandung pasti mengharapkan kebaikan pada anaknya, maka dari itu seorang guru yang baik adalah guru yang mengharapkan kebaikan pada anak didiknya. ${ }^{17}$

Namun jika dikaji lebih dalam kitab ini sudah cukup memuat wasiat- wasiat tentang pendidikan moral. Kitab ini mengemas pendidikan moral dalam bentuk bab per bab sebanyak 20 bab dengan disertai uraian konsep dari tema yang dibicarakan, Sebagai kitab yang berisi tentang wasiatwasiat moral, kitab Washoya juga mencakup beberapa nilai pendidikan karakter. Nilai pendidikan karakter dalam kitab ini di mulai dengan relasi antara guru dan murid yang diumpamakan sebagaimana orang tua dan anak kandung. Guru adalah orang yang berperan sebagi penasehat, pendidikan, pembina rohani dan suri tauladan. Namun pengawasan guru tidak bisa dijadikan sandaran utama, karena pengawasan diri sendiri itu lebih utama. Seperti wasiat yang tercantum dalam kitab Washoya;

"Wahai anakku, jangan engkau hanya menanti saran dan kritik dariku, sesungguhnya mawas diri itu lebih utama dan lebih besar manfaatnya." 18

\section{Analisis Pendidikan Karakter Dalam Kitab Washoya Al Abaa' Lil Abnaa'}

a. Pengertian Pendidikan karakter

Pendidikan karakter adalah usaha sadar dan terencana yang dilakukan oleh seorang pendidik untuk membentuk tabiat yang baik pada seorang santri (anak didik), sehingga terbentuk manusia yang taat kepada Allah Pembentukan tabiat ini dilakukan oleh pendidik yang secara bertahap dan terus-menerus tanpa adanya paksaan dari pihak manapun. Syaikh Muhammad Syakir dalam wasiatnya:

"Wahai anakku, semoga Allah memberimu petunjuk dan pertolongan untuk selalu beramal shalih. Sesungguhnya bagiku engkau ibarat anak yang berada di sisi ayah yang dicintainya. Aku akan bahagia dirimu berbadan sehat, berpendirian kuat, suci hati, berakhlak mulia,menjaga adab, menjauhi perkataan tercela, lemah lembut dalam bergaul, menyayangi

\footnotetext{
${ }^{16}$ Syaikh Muhammad Syakir, W ashoya Al-Abaa Lil-Abna (Semarang: Toha Putra), h. 47

17 Irfan Firdaus, Dialog Agama dan Budaya Lokal, dalam Jurnal Penelitian Agama UIN Sunan

Kalijaga Vol XV (Yogyakarta: Lembaga Penelitian UIN Sunan Kalijaga, 2006), h.483

18 Syaikh Muhammad Syakir, Terjemah Washoya Al-Abaa Lil-Abna, Penerjemah Achmad Sunarto (Surabaya: Al Miftah), h.14
} 
sesame, menolong fakir, belaskasih terhadp yang lemah, pemaaf, tidak meninggalkan shalat, dan tidak menunda-nunda waktu untuk beribadah kepada Pencipta, Pemilik, Pemelihara, Penguasamu"19

Jadi pendidikan karakter dilaksanakan agar terwujudnya kesadaran antara pendidik dan peserta didik serta proses pembelajaran agar peserta didik dapat secara aktif mengembangkan potensi diri untuk memiliki kekuatan spiritual keagamaan, pengendalian diri, kepribadian, kecerdasan, moral yang baik, serta keterampilan yang diperlukan dalam hidup bermasyarakat, berbangsa, dan bernegara. ${ }^{20}$

\section{b. Landasan Pendidikan Karakter}

Pendidikan karakter adalah pendidikan yang berpedoman pada Al- Qur'an dan Al- Hadits, mengenai landasan pendidikan moral yang bersumber dari Al-Qur'an adalah QS. Lukman ayat 12-19 yang berisikan tentang nasehat Lukmanul Hakim kepada anaknya. Yang Artinya;

Ayat (12). dan Sesungguhnya telah Kami berikan hikmat kepada Luqman, Yaitu: "Bersyukurlah kepada Allah. dan Barangsiapa yang bersyukur (kepada Allah), Maka Sesungguhnya ia bersyukur untuk dirinya sendiri; dan Barangsiapa yang tidak bersyukur, Maka Sesungguhnya Allah Maha Kaya lagi Maha Terpuji". (13). dan (ingatlah) ketika Luqman berkata kepada anaknya, di waktu ia memberi pelajaran kepadanya: "Hai anakku, janganlah kamu mempersekutukan Allah, Sesungguhnya mempersekutukan (Allah) adalah benar-benar kezaliman yang besar". (14). dan Kami perintahkan kepada manusia (berbuat baik) kepada dua orang ibu- bapanya; ibunya telah mengandungnya dalam Keadaan lemah yang bertambah- tambah, dan menyapihnya dalam dua tahun. bersyukurlah kepadaku dan kepada dua orang ibu bapakmu, hanya kepada-Kulah kembalimu. (15). dan jika keduanya memaksamu untuk mempersekutukan dengan aku sesuatu yang tidak ada pengetahuanmu tentang itu, Maka janganlah kamu mengikuti keduanya, dan pergaulilah keduanya di dunia dengan baik, dan ikutilah jalan orang yang kembali kepada-Ku, kemudian hanya kepadaKulah kembalimu, Maka Kuberitakan kepadamu apa yang telah kamu kerjakan. (16). (Luqman berkata): "Hai anakku, Sesungguhnya jika ada (sesuatu perbuatan) seberat biji sawi, dan berada dalam batu atau di langit atau di dalam bumi, niscaya Allah akan mendatangkannya (membalasinya). Sesungguhnya Allah Maha Halus [1181] lagi Maha mengetahui. (17). Hai anakku, dirikanlah shalat dan suruhlah (manusia) mengerjakan yang baik dan cegahlah (mereka) dari perbuatan yang mungkar dan bersabarlah terhadap apa yang menimpa kamu. Sesungguhnya yang demikian itu Termasuk hal-hal yang diwajibkan (oleh Allah). (18). dan janganlah kamu memalingkan mukamu dari manusia (karena sombong) dan janganlah kamu berjalan di muka bumi dengan angkuh. Sesungguhnya Allah tidak menyukai orang-orang yang sombong lagi membanggakan diri. (19). dan sederhanalah kamu dalam berjalan dan lunakkanlah suaramu. Sesungguhnya seburuk-buruk suara ialah suara keledai.” 21

\section{c. Tujuan Pendidikan Karakter}

Tujuan dilaksanakannya pendidikan karakter yaitu menjadikan manusia yang bisa bernilai baik bagi manusia lain. Dalam kitab Washoya, Syaikh Muhammad Syakir berwasiat:

\footnotetext{
"Sesungguhnya aku menginginkanmu menjadi baik. Karena itu bantulah aku menyempurnakan kebaikan kepadamu dengan cara mentaati dan mengikuti nasehatku, berupa pengalaman moral yang mulia."
}

${ }^{19}$ Ibid, h. 9 - 10

20 Abdul Latif, Pendidikan Berbasis Nilai Kemasyarakatan, (Bandung: PT. Revika Aditama, 2007), h. 7.

${ }^{21}$ Departemen Agama RI, Al-Qur'an dan Terjemahnya (Jakarta: CV. Pustaka Agung Harapan, 2006), h.413 
"Akhlak yang baik adalah hiasan bagi manusia, baik ketika sendirian, bersama teman-teman, keluarga atau sanak kerabatnya. Oleh karena itu, jadilah engkau seorang yang berbudi baik, tentu orang-orang akan menghormatimu dan mencintaimu." 22

Begitu pula yang dikatakan oleh Ibnu Maskawaih, bahwa tujuan pendidikan karakter adalah terwujudnya sikap batin yang mampu mendorong secara spontan untuk melahirkan semua perbuatan yang bernilai baik. ${ }^{23}$ Sehingga mencapai kesempurnaan dan memperoleh kebahagiaan yang sejati dan sempurna. Seperti kutipan yang disimpulkan oleh suwito bahwa tujuan pendidikan moral menurut pemikiran Ibnu Maskawaih adalah terciptanya manusia yang berperilaku ketuhanan yang ada dalam diri manusia secara spontan. Demikianlah beberapa tujuan pendidikan karakter dalam kitab Washoya Al-Abaa Lil Abna yang secara umum dapat kita simpulkan dan kita klasifikasi menjadi beberapa bagian, sebagai berikut: 1) Pesan Taqwa Kepada Allah, 2) Kewajiban terhadap Allah dan RasulNya, 3) Kewajiban terhadap Guru, 4) Hak Dan Kewajiban Terhadap Kedua Orang Tua, 5) Hak dan Kewajiban terhadap Teman.

\section{d. Nilai-nilai Pendidikan Karakter}

Nilai-nilai pendidikan karakter yang terangkum dalam kitab Washoya dituangkan dalam bentuk wasiat. Selanjutnya nilai-nilai pendidikan karakter tersebut terangkum dalam beberapa wasiat akhlak, ${ }^{24}$ di antaranya adalah: 1) Tata cara menuntut ilmu, dengan sungguh-sungguh, semangat dan tidak menyia-nyiakan waktu, tidak bersuara keras, hormat, mencari ridlonya dan mintalah Do'a. 2) Adab Belajar dan Berdiskusi, diskusi sangat membantu anak untuk mengambil keputusan yang lebih baik dari pada memutuskan sendiri 3) Adab Berolah Raga dan Berjalan di Jalan Umum guna menjaga kesehatan dan ketentraman orang lainnya, 4) Adab dalam suatu pertemuan, 5) Adab Makan dan Minum, 6) Adab Beribadah dan di dalam Masjid, 7) Anjuran bersifat Jujur, 8) Anjuran bersifat Amanah, 9) Gunjingan, Adu Domba, Dengki, Sombong dan Lalai Beribadah kepada Allah.

\section{Metode Pendidikan Karakter Dalam Kitab Washoya Al Abaa' Lil Abnaa'}

Beberapa metode pembelajaran dalam kitab Washoya Al Abaa' Lil Abnaa' yang diantaranya adalah;

a. Metode Menghafal. "Wahai anakku, perbanyaklah muzakarah (mengkaji ulang) berbagai pelajaran yang telah kamu peroleh. Karena karena sesungguhnya petaka bagi ilmu pengetahuan adalah lupa". ${ }^{25}$

b. Metode Diskusi. Wahai anakku, diskusi sesama pelajar dalam membahas kajian ilmiah, banyak memberikan manfaat, di antaranya: memperkuat pemahaman, memperlancar pembicaraan, membantu mengambil pelajaran dari suatu masalah yang di maksud,dan melahirkan generasi pencari ilmu selanjutnya" 26

c. Metode Nasehat. (Mau'izhah) 'Wahai anakku, seandainya kamu mau menerima nasihat dari sesorang, maka akulah orang yang pantas kamu terima nasihatnya, Aku adalah gurumu, pendidikmu yang membantu memelihara jiwamu. Kamu tidak akan mendapatkan seorangpun yang mengharapkan kebaikan dari dirimu (sesudah orang tuamu) kecuali aku,27

\footnotetext{
22 Syaikh Muhammad Syakir, Terjemah Washoya Al-Abaa Lil-Abna, Penerjemah Achmad Sunarto (Surabaya: Al Miftah), h.13

${ }^{23}$ Busyairi Majidi, Konsep Pendidikan Moral para Filosof Muslim, (Yogyakarta, Al-Amin Press, 1997), h. 70

24 Syakir, Washoya, h.40

25 Syakir, Washoya, h. 54

${ }^{26}$ Ibid, h. 57

${ }^{27}$ Ibid, h. 10
} 
Kata mau'izhah berasal dari kata wa'₹̧u, yang berarti nasehat yang terpuji, memotivasi untuk melaksanakannya dengan perkataan yang lembut. Allah berfirman di dalam Qs. Al Baqaroh 232, yang Artinya:

"Itulah yang dinasehatkan kepada orang-orang yang beriman di antara kamu kepada Allah dan hari kemudian. itu lebih baik bagimu dan lebih suci. Allah mengetahui, sedang kamu tidak mengetahui." (Qs. Al- Baqarah: 232).

d. Metode Pembiasaan. "Wahai anakku, iffah adalah bagian dari akhlak dari orang-orang yang menjaga kebaikan dan bagian dari sifat orang-orang yang beramal baik. Karena itu kamu harus memiliki akhlak (iffah) ini, agar menjadi tabiat yang tertanam dalam dirimu". ${ }^{28}$

Pembiasaan yang dilakukan sejak dini atau sejak kecil akan memebawa kegemaran dan kebiasaan tersebut menjadi semacam adat kebiasaan sehingga menjadi bagian tidak terpisahkan dari kepribadiannya. Al-Ghazali mengatakan: "Anak adalah amanah orang tuanya. hatinya yang bersih adalah permata berharga nan murni, yang kosong dari setiap tulisan dan gambar. Hati itu siap menerima setiap tulisan dan cenderung pada setiap yang ia inginkan. Oleh karena itu, jika dibiasakan mengerjakan yang baik, lalu tumbuh di atas kebaikan itu maka bahagialah ia didunia dan akhirat, orang tuanya pun mendapat pahala bersama. ${ }^{29}$

e. Metode Kisah. "Wahai anakku, Rasulullah SAW pernah mengembalahkan kambing sebelum beliau diutus menjadi nabi, kemudian beliau pernah berdagang sampai beliau diutus menjadi nabi, dan beliau tidak pernah meninggalkan usaha untuk hidup bahkan sampai beliau di bawah bayang-bayang tombaknya (berperang). Dan Abu Bakar As Syidiq juga seorang saudagar sampai beliau menjadi khalifah pertama. Demikian juga para sahabat nabi yang lain, tabiin dan salafus shalih, mereka bekerja untuk mencukupi kebutuhannya. Dan tidaklah ilmu yang mereka miliki tidak menghalangi mereka bergaul dengan sesama manusia dalam bekerja dan berusaha dalam mencari nafkahyang halal, bahkan mereka menjadi tauladan yang baik dalam bekerja." 30

Abdurrahman An-Nahlawi mengatakan kisah mengandung aspek pendidikan yaitu dapat mengaktifkan dan membangkitkan kesadaran pembacanya, membina perasaan ketuhanan dengan cara mempengaruhi emosi, mengarahkan emosi, mengikutsertakan psikis yang membawa pembaca larut dalam setting emosional cerita, topic cerita memuaskan pikiran. Selain itu kisah dalam Al-Quran bertujuan mengkokohkan wahyu dan risalah para Nabi, kisah dalam Al-Quran memberi informasi terhadap agama yang dibawa para Nabi berasal dari Allah, kisah dalam Al-Quran mampu menghibur umat Islam yang sedang sedih atau tertimpa musibah. ${ }^{31}$ Dari kutipan tersebut dapat diambil pemahaman bahwa cerita/kisah dapat menjadi metode yang baik dalam rangka membentuk moral dan kepribadian anak.

f. Metode Dialog. "Wahai anakku, apabilah dirimu tidak menuruti nasihatku, maka siapakah yang akan kamu ikuti? Dan apalah artinya selama ini kamu memaksa dirimu duduk (belajar) dihadapanku?"

"Wahai anakku, sesungguhnya seseorang guru menyayangi anak muridnya yang shalih dan beradab. Apakah dirimu suka jika guru yang telah mendidikmu tidak ridha dan tidak mengharapkan kebaikan dari dirimu?"

Abdurrrahman An-Nahlawi mengatakan pembaca dialog akan mendapat keuntungan berdasarkan karakteristik dialog, yaitu topik dialog yang disajikan dengan pola dinamis

\footnotetext{
${ }^{28}$ Ibid, h.103

29 Muhammad Rabbi Muhammad Jauhari, Akblaquna, Penerjemah Dadang Sobar Ali (Bandung: Pustaka Setia: 2006), h.109

${ }^{30}$ Syakir, Washoya, h.139

${ }^{31}$ Departemen Agama RI, Al-Quran dan terjemah dan Penjelasan Ayat Abkam, (Jakarta: Pena Pundi Aksara,2006., h.596
}

\section{Nor Mubin-Pendidikan Karakter pada Anak Perspektif Washoya Al Abaa' Lil Abnaa'}


sehingga materi tidak membosankan, pembaca tertuntun untuk mengikuti dialog hingga selesai, melalui dialog perasaan dan emosi pembaca akan terbangkitkan, topik pembicaraan disajikan bersifat realistik dan manusiawi. Dalam Al-Quran banyak memberi informasi tentang dialog, di antara bentuk-bentuk dialog tersebut adalah dialog khitabi, taabbudi, deskriftif, naratif, argumentative serta dialog Nabawiyah. ${ }^{32}$

g. Metode Keteladanan. 'Wahai anakku, jauh sekali antara orang yang membaca al Qur'an tapi dia tidak paham maksud dan makna yang di bacanya, dengan orang yang membaca al Qur'an dan dia memahami maksud dan makna yang dibacanya. Adapun orang yang jenis pertama seperti orang buta yang berjalan dijalan raya dan dia tidak bisa melihat apapun. Sementara orang yang jenis kedua seperti orang yang jernih pengelihatannya dan dengan pengelihatan tersebut dia mampu menyelamatkan diri (tidak tergelincir). ${ }^{\prime 33}$

Muhammad Bin Muhammad Al-Hamd mengatakan pendidik itu besar dimata anak didiknya, apa yang dilihat dari gurunya akan ditirunya, karena murid akan meniru dan meneladani apa yang dilihat dari gurunya. Keteladanan menjadi titik sentral dalam mendidik dan membina karakter anak didik, kalau pendidik bermoral baik ada kemungkinan anak didiknya juga bermoral baik begitu juga sebaliknya.

h. Metode Targhib wa Tahdib. "Wahai anakku, sesungguhnya di dalam al Qur'an Allah menyatakan telah melaknat orang-orang yang berdusta. Apakah kamu rela jika kamu menjadi orang yang dilaknatdi sisi Allah padahal kamu adalah orang yang belajar ilmu agama." ${ }^{34}$

Targhib adalah janji yang disertai bujukan dan rayuan untuk menunda kemaslahatan, kelezatan, dan kenikmatan. Sedangkan tarhib adalah ancaman, intimidasi melalui hukuman, dari kutipan tersebut dapat dipahami bahwa metode pendidikan karakter dapat berupa janji/pahala/hadiah dan dapat juga berupa hukuman. ${ }^{35}$

Konten dalam kitab Washoya $A l$ Abaa' lil Abnaa' sudah sesuai dengan konsep pendidikan karakter pada anak yang selama ini kita butuhkan. Konsep pendidikan karakter perspektif Syaikh Mubammad Syakir dalam kitab tersebut di antaranya ialah konsep berakhlak kepada Allah dan Rasul-Nya, terhadap ilmu, kepada guru, kepada orang tua, kepada teman, kepada masyarakat, kepada diri sendiri, dan terhadap negara. Di dalam kitab Washoya Al Abaa' lil Abnaa'juga terdapat metode-metode pembelajaran yang relevan diterapkan pada masa sekarang.

Pemaparan yang digambarkan secara ringkas di atas dan secara sistematis pada sub bab sebelumnya, semoga dapat menjadi alternative bagi praktisi pendidikan dalam mengembangkan pendidikan karakter pada anak yang berbasis Islami. Meski demikian, manfaat dari nilai-nilai karakter yang terkandung di dalamnya bermanfaat pula bagi mashlahat masyarakat. Sehingga hal tersebut dapat bermanfaat baik secara vertikal antara hubungan seorang hamba kepada Allah Swt. maupun secara horizontal antara hubungan individu kepada sesama makhluk lainnya.

\footnotetext{
32 Abdurrahman An-Nahlawi, Ushulut Tarbiyah Islamiyah Wa Asalibiha fii Baiti wal Madrasati wal Mujtama' Penerjemah. Shihabuddin, (Jakarta: Gema Insani Press:1996)., h.206

33 Syakir, Washoya, h. 154

34 Syakir, W ashoya, h. 89

35 Abdurrahman an-Nahlawi, Ibid., h.296
} 


\section{Kesimpulan}

Dari pembahasan dan analisa di atas, maka dapat disimpulkan sebagai berikut:

1. Secara umum konsep pendidikan karakter memiliki empat dasar, yakni pendidikan karakter berbasis nilai religius (konservasi moral), pendidikan karakter bernilai budaya (konservasi lingkungan), pendidikan karakter berbasis lingkungan, pendidikan karakter berbasis potensi diri (konservasi humanis). Pendidikan karakter bertujuan untuk menanamkan nilai-nilai kebaikan dan membentuk manusia secara keseluruhan serta mengembangkan potensi yang dimilikinya. Yang tidak hanya memiliki kepandaian dalam berpikir tetapi juga respek terhadap lingkungan, dan juga melatih setiap potensi diri anak agar dapat berkembang ke arah yang positif. Ada 18 nilai pendidikan karakter yang bersumber dari agama, pancasila, budaya, dan tujuan pendidikan nasional, yaitu: (1) religius, (2) jujur, (3) toleransi, (4) disiplin, (5) kerja keras, (6) kreatif, (7) mandiri, (9) rasa ingin tahu, (10) semangat kebangsaan, (11) cinta tanah air, (12) menghargai prestasi, (13) bersahabat atau komunikatif, (14) cinta damai, (15) gemar membaca, (16) peduli ligkungan, (17) peduli social, (18) tanggung jawab. Metode pendidikan karakter secara umum ada lima mengajarkan pemahaman konseptual, keteladanan, menentukan prioritas, raktis prioritas, Refleksi.

2. Hasil analisa dalam kitab Washoya Al-Abaa' Lil Abnaa' dapat disimpulkan menjadi beberapa tujuan pendidikan karakter diantaranya klasifikasi pesan taqwa kepada Allah, kewajiban terhadap Allah dan RasulNya, kewajiban terhadap guru, hak dan kewajiban terhadap kedua orang tua, hak dan kewajiban terhadap teman. Adapun nilai-nialai pendidikan karakter dalam kitab washoya al-abaa' lil abnaa' dapat diklasifikasikan sebagai berikut: Tata Cara Menuntut Ilmu, Adab Belajar Dan Berdiskusi, Adab Berolah Raga dan Berjalan Di Jalan Umum, Adab Dalam Suatu Pertemuan, Adab Makan Dan Minum, Adab Beribadah Dan Didalam Masjid, Anjuran Bersifat Jujur, Anjuran Bersifat Amanah, Gunjingan, Adu Domba, Dengki, Sombong Dan Lalai Dalam Beribadah Kepada Allah.

Sedangkan metode pendidikan karakter dalam kitab Washoya Al-Abaa' Lil Abnaa' dapat disimpulkan menjadi metode diskusi, metode menghafal, metode nasehat (mau'izhah), metode pembiasaan, metode kisah, metode keteladanan, metode dialog, metode targhib wa tahdib, metode targhib wa tahdib. 


\section{Daftar Pustaka}

Abdul Aziz Abdul Majid, Al-Qissah fi al-Tarbiyah, Bandung: Remaja Rosdakarya, 2001, Terj. Neneng Yanti dan Dzulkifli

Abdul Latif, Pendidikan Berbasis Nilai Kemasyarakatan, Bandung: PT. Revika Aditama, 2007

Abdullah, Biografi Syaikh Mubammad Syakir, (http://www.scribd.com), diakses pada: 25, Maret 2020

Abdurrahman An-Nahlawi, Ushulut Tarbiyah Islamiyah Wa Asalibiha fii Baiti wal Madrasati wal Mujtama’ Penerjemah. Shihabuddin, Jakarta: Gema Insani Press:1996.

Basri, Hasan. Filsafat Peendidikan Islam, Bandung: Pustaka Setia, 2009

Busyairi Majidi, Konsep Pendidikan Moral para Filosof Muslim, Yogyakarta, Al- Amin Press, 1997.

Departemen Agama RI, Al-Qur'an dan Terjemahnya, Jakarta: CV. Pustaka Agung Harapan, 2006

Doni Koesoema A. Pendidikan Karakter; Strategi Mendidik Anak Di Zaman Modern, Jakarta: Grasindo, 2007

Haidar Putra Daulay, Pendidikan Islam dalam Sistem Pendidikan Nasional di Indonesia, Jakarta: Prenada Media Group, 2007

Irfan Firdaus, Dialog Agama dan Budaya Lokal, dalam JurnalPenelitian Agama UIN Sunan Kalijaga Vol XV, Yogyakarta: Lembaga Penelitian UIN Sunan Kalijaga, 2006

Martin Van Bruinessen, Kitab Kuning Pesantren dan Tarekat: Tradisi Islam di Indonesia, Bandung: Mizan, 1995.

Muhammad bin Ibrahim al- Hamd, Maal Muallimin, Penerjemah, Ahmad Syaikhu, Jakarta: Darul Haq, 2002, bandingkan dengan Fuad bin Abdul Azizi al Syalhub, Al-Muallim alAwwal shalallaahu alaihi Wa Sallam Qudwah Likulli Muallim wa Muallimah, ,penerjemah. Abu Haekal, Jakarta: Zikrul Hakim,2005.

Muhammad Rabbi Muhammad Jauhari, Akblaquna, Penerjemah Dadang Sobar Ali, Bandung: Pustaka Setia: 2006.

Nurul Zuriah, Pendidikan Moral dan Budi Pekerti dalam perspektif Perubahan, Jakarta: PT. Bumi Aksara, 2007

Syaikh Muhammad Syakir, Terjemah Washoya Al-Abaa Lil-Abna, Penerjemah Achmad Sunarto, Surabaya: Al Miftah

Zainuddin, Ahli Hadist, Sumber:http://www.ahlulhadis.wordpress.com diakses pada 25, Maret 2020 . 